Stefaniak Martyna, Pietrzak Zofia, Dzikowski Piotr, Nowicka Emilia, Obel Michał, Piecewicz-Szczęsna Halina. Efficacy and safety of fenfluramine in the treatment of Dravet syndrome - literature review. Journal of Education, Health and Sport. 2022;12(1):106116. eISSN 2391-8306. DOI http://dx.doi.org/10.12775/JEHS.2022.12.01.008 https://apcz.umk.pl/JEHS/article/view/JEHS.2022.12.01.008 https://zenodo.org/record/5849877

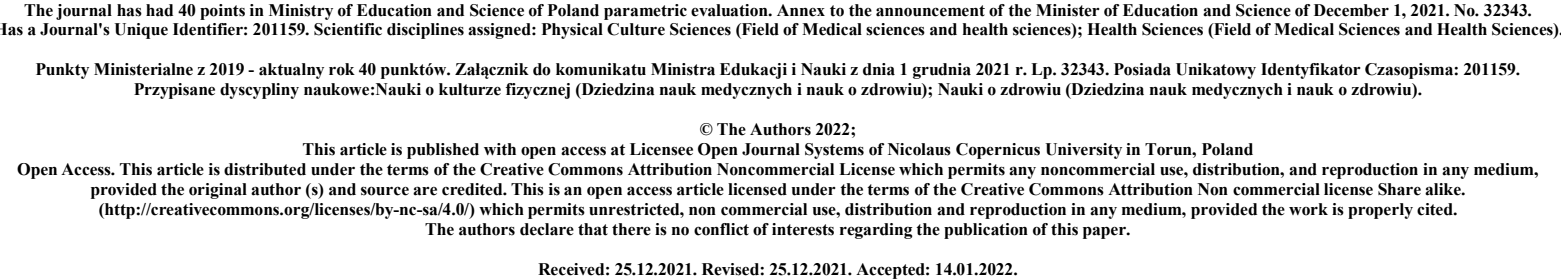

Received: 25.12.2021. Revised: 25.12.2021. Accepted: 14.01.2022.

\title{
Efficacy and safety of fenfluramine in the treatment of Dravet syndrome - literature review
}

Martyna Stefaniak ${ }^{1}$, martynastefaniakk@gmail.com;

https://orcid.org/0000-0002-8036-8379

Zofia Pietrzak ${ }^{1}$, zofer.pietrzak@gmail.com;

https://orcid.org/0000-0001-8469-6225

Piotr Dzikowski ${ }^{1}$, piotrekdzikowski22@gmail.com;

https://orcid.org/0000-0002-6335-9171

Emilia Nowicka', e.nowicka22@gmail.com;

https://orcid.org/0000-0002-2743-1551

Michał Obel' ${ }^{1}$, michalobe13@gmail.com;

https://orcid.org/0000-0003-1237-8732

Halina Piecewicz-Szczęsna ${ }^{2}$, halpiec@gmail.com;

https://orcid.org/0000-0002-0573-7226

1. Students' Scientific Association at the Chair and Department of Epidemiology, Medical University of Lublin, ul. Radziwiłłowska 11 (Collegium Medicum), 20-080 Lublin, Poland

2. Chair and Department of Epidemiology, Medical University of Lublin, ul. Radziwiłłowska 11 (Collegium Medicum), 20-080 Lublin, Poland

\footnotetext{
Abstract

Dravet Syndrome is a severe, drug-resistant, and rare epileptiform disorder that is typically presented in the first year of life in an otherwise healthy child. It is characterized by prolonged seizures that are often resistant to current anti-epileptic drug regimens, which made them poorly controlled, and almost $50 \%$ of patients experience at least four tonic-clonic seizures per month. There are three new medicines: stiripentol, cannabidiol, and fenfluramine,
} 
with documented efficacy and safety as adjunctive therapies in pharmacoresistant Dravet syndrome treatment.

This study aimed to assess the efficacy and safety of fenfluramine in the treatment of Dravet syndrome. Our study material consisted of publications, which were found in PubMed, Google Scholar, and Embase databases. In order to find the proper publications, the search has been conducted with the use of a combination of keywords like: "fenfluramine", "Dravet syndrome", "epilepsy treatment", "Dravet syndrome pediatric patients". The first step was to find proper publications from the last 10 years. The second step was to carry out an overview of the found publications.

Results of mentioned studies proved that in Dravet syndrome, fenfluramine provided a significantly greater reduction in convulsive seizure frequency compared with placebo. No patient developed valvular heart disease or pulmonary arterial hypertension, the side effects that occurred during its use were mild and the drug was generally well-tolerated. The bioequivalence and tolerability of single oral doses of fenfluramine hydrochloride oral solution in the fed and fasted states support drug administration without regard to meals. Fenfluramine may represent a new important treatment option for Dravet syndrome.

Key words: fenfluramine; Dravet syndrome; epilepsy treatment; seizure frequency; pharmacokinetics

\section{INTRODUCTION AND PURPOSE}

Dravet Syndrome (DS) is a severe, drug-resistant, and rare epileptiform disorder that is typically presented in the first year of life in an otherwise healthy child. It is characterized by prolonged seizures that are often resistant to current anti-epileptic drug (AED) regimens, which made them poorly controlled, and almost $50 \%$ of patients experience at least four tonic-clonic seizures per month $[1,2,3]$. There are three new medicines: stiripentol (STP), cannabidiol, and fenfluramine, with documented efficacy and safety as adjunctive therapies in pharmacoresistant DS treatment [4].

Fenfluramine hydrochloride, an amphetamine derivative, launched as an anorectic agent has classically been described as acting pharmacologically through a serotonergic mechanism, initially utilized as a drug in the 1970s was withdrawn from the market in 1997 when it was found to cause cardiac valvulopathy $[3,5,6,7,8]$. The drug was approved again in the U.S. and Europe in 2020 for the treatment of seizures associated with DS, through a controlled access program aimed at minimizing safety risks [8]. From the ongoing clinical trial data, it is evident that fenfluramine is proving to be a promising antiepileptic drug with very favorable pharmacokinetics and with a good overall safety profile when used at a lower dosage $(0.2-0.7 \mathrm{mg} / \mathrm{kg} /$ day) [9]. Furthermore, the latest researches also support long-term improvements in executive functions in these patients. Fenfluramine demonstrated modulatory activity at $\sigma 1$ receptors, a type of cell membrane receptor common in nerve cells, in vitro and in vivo in addition to its known serotonergic activity what may develop possible new $\sigma 1$ receptor mechanism underpinning fenfluramine's central nervous system effects, 
which may contribute to its antiseizure activity in DS and positive effects observed on executive functions in clinical studies [10].

This study aimed to assess the efficacy and safety of fenfluramine in the treatment of DS. Our study material consisted of publications, which were found in PubMed, Google Scholar, and Embase databases. In order to find the proper publications, the search has been conducted with the use of a combination of keywords like: "fenfluramine", "Dravet syndrome", "epilepsy treatment", "Dravet syndrome pediatric patients". The first step was to find proper publications from the last 10 years. The second step was to carry out an overview of the found publications.

\section{RESULTS}

\section{Efficacy of fenfluramine in the treatment of DS}

In a randomized, double-blind, placebo-controlled clinical trial, Lagae et al. enrolled children and young adults with DS. After a 6-week observation period to establish baseline monthly convulsive seizure frequency (MCSF), patients were randomly assigned through an interactive web response system in a 1:1:1 ratio to placebo, fenfluramine $0.2 \mathrm{mg} / \mathrm{kg}$ per day, or fenfluramine $0.7 \mathrm{mg} / \mathrm{kg}$ per day, added to existing antiepileptic agents for 14 weeks. The primary outcome was the change in the mean monthly frequency of convulsive seizures during the treatment period compared with baseline in the $0.7 \mathrm{mg} / \mathrm{kg}$ per day group versus placebo; $0.2 \mathrm{mg} / \mathrm{kg}$ per day versus placebo was assessed as a key secondary outcome. Analysis was by modified intention to treat. Safety analyses included all participants who received at least one dose of study medication.

Between Jan 15, 2016, and Aug 14, 2017, they assessed 173 patients, of whom 119 patients (mean age 9.0 years, 64 [54\%] male) were randomly assigned to receive either fenfluramine $0.2 \mathrm{mg} / \mathrm{kg}$ per day (39), fenfluramine $0.7 \mathrm{mg} / \mathrm{kg}$ per day (40) or placebo (40). During treatment, the median reduction in seizure frequency was $74.9 \%$ in the fenfluramine $0.7 \mathrm{mg} / \mathrm{kg}$ group, $42.3 \%$ in the fenfluramine $0.2 \mathrm{mg} / \mathrm{kg}$ group, and $19.2 \%$ in the placebo group. The study met its primary efficacy endpoint, with fenfluramine $0.7 \mathrm{mg} / \mathrm{kg}$ per day showing a $62 \cdot 3 \%$ greater reduction in mean MCSF compared with placebo; fenfluramine $0 \cdot 2$ $\mathrm{mg} / \mathrm{kg}$ per day showed a $32.4 \%$ reduction in mean MCSF compared with placebo. The most common adverse events were decreased appetite, diarrhea, fatigue, lethargy, somnolence, and decreased weight. Echocardiographic examinations revealed valve function within the normal physiological range in all patients during the trial and no signs of pulmonary arterial hypertension (PAH) [11].

A double-blind, placebo-controlled, parallel-group randomized clinical trial was conducted in multiple centers by Nabbout et al. to determine whether fenfluramine reduced monthly convulsive seizure frequency relative to placebo in patients with DS who were taking stiripentol-inclusive regimens. Eligible patients were children aged 2 to 18 years with a confirmed clinical diagnosis of DS who were receiving stable, stiripentol-inclusive antiepileptic drug regimens. Patients with 6 or more convulsive seizures during the 6 -week baseline period were randomly assigned to receive fenfluramine, $0.4 \mathrm{mg} / \mathrm{kg} / \mathrm{d}$, or a placebo. After titration ( 3 weeks), patients' assigned dosages were maintained for 12 additional weeks. 
Caregivers recorded seizures via a daily electronic diary. The primary efficacy endpoint was the change in mean monthly convulsive seizure frequency between fenfluramine and placebo during the combined titration and maintenance periods relative to baseline.

A total of 115 eligible patients were identified; of these, 87 patients (mean [SD], age 9.1 [4.8] years; 50 male patients [57\%]; mean baseline frequency of seizures, approximately 25 convulsive seizures per month) were enrolled and randomized to fenfluramine, 0.4 $\mathrm{mg} / \mathrm{kg} / \mathrm{d}(\mathrm{n}=43)$ or placebo $(\mathrm{n}=44)$. Patients treated with fenfluramine achieved a $54.0 \%$ greater reduction in mean monthly convulsive seizure frequency than those receiving the placebo. With fenfluramine, $54 \%$ of patients demonstrated a clinically meaningful $(\geq 50 \%)$ reduction in monthly convulsive seizure frequency vs $5 \%$ with placebo. The median longest seizure-free interval was 22 days with fenfluramine and 13 days with placebo. The most common adverse events were decreased appetite, fatigue, diarrhea, and pyrexia. Cardiac monitoring demonstrated no clinical or echocardiographic evidence of valvular heart disease (VHD) or PAH [12].

The objective of Sullivan et al. analysis was to assess the longer-term safety and efficacy of fenfluramine in patients who completed one of the double-blind studies and entered an open-label extension (OLE) study. Patients enrolling in the OLE study initiated fenfluramine at $0.2 \mathrm{mg} / \mathrm{kg} / \mathrm{d}$ regardless of their treatment assignment in the double-blind study. After 4 weeks, the fenfluramine dose could be titrated based on efficacy and tolerability to a maximum of $0.7 \mathrm{mg} / \mathrm{kg} / \mathrm{d}$ or a maximum of $0.4 \mathrm{mg} / \mathrm{kg} / \mathrm{d}$ in patients receiving concomitant STP. The number and type of seizures were recorded daily in an electronic diary, and safety, including echocardiography, was assessed at Months 1, 2, and 3, and at 3-month intervals thereafter.

A total of 232 patients were enrolled as of March 13, 2018. During this analysis period, patients were treated for a median of 256 days. Over the entire OLE analysis period, the median decrease in convulsive seizure frequency compared to baseline in the doubleblind studies was $-66.8 \%$. The median reduction in seizure frequency was similar in patients $<6(-75.7 \%)$ and $\geq 6$ years old $(-64.7 \%)$. The most commonly reported adverse events included pyrexia, nasopharyngitis, and decreased appetite. No VHD or PAH was observed [13].

DS patients were treated with fenfluramine in the Zogenix Early Access Program at four Italian pediatric epilepsy centers. Fenfluramine was administered as an add-on, twice daily at an initial dose of $0.2 \mathrm{mg} / \mathrm{kg} / \mathrm{d}$ up to $0.7 \mathrm{mg} / \mathrm{kg} / \mathrm{d}$. Seizures were recorded in a diary. Adverse events (AEs) and cardiac safety (with Doppler echocardiography) were investigated every 3 to 6 months.

Fifty-two patients were enrolled, with a median age of 8.6 years. Forty-five $(86.5 \%)$ patients completed the efficacy analysis. The median follow-up was 9.0 months. At the last follow-up visit, there was a $77.4 \%$ median reduction in convulsive seizures. Thirty-two patients $(71.1 \%)$ had a $\geq 50 \%$ reduction of convulsive seizures, $24(53.3 \%)$ had a $\geq 75 \%$ reduction, and five $(11.1 \%)$ were seizure-free. The most common adverse event was decreased appetite. No echocardiographic signs of VHD or PAH were observed. There was no correlation between the type of genetic variants and response to fenfluramine [14].

Deriving numbers needed to treat (NNTs) to achieve clinically desirable response levels can further inform individual decision-making. Sullivan et al. calculated the NNT with 
fenfluramine to achieve "clinically meaningful" ( $\geq 50 \%)$ or "profound" ( $\geq 75 \%)$ MCSF reductions in patients with DS. NNT to achieve $\geq 50 \%$ or $\geq 75 \%$ MCSF reduction was assessed using longitudinal data from two phase 3 studies for adjunctive fenfluramine in DS patients aged 2-18 years. NNT was calculated: 1/((Experimental-Responder Rate)-(ControlResponder Rate)). In Study 1, NNTs to achieve $\geq 50 \%$ and $\geq 75 \%$ MCSF reduction were 1.8 and 2.1 at $0.7 \mathrm{mg} / \mathrm{kg} /$ day fenfluramine. In Study 2, these NNTs were 2.0 and 3.1, respectively. These results were seen as early as Weeks 6-7 and were sustained through Weeks 14-15.

For every two to three patients with DS treated with fenfluramine in these trials, one patient achieved $\geq 50 \%$ or $\geq 75 \%$ MCSF reduction, respectively, compared with placebo. Responder analyses and NNTs can aid in clinical decision-making by offering clinically important information that is complementary to the population mean data on the chance of an individual patient achieving meaningful levels of MCSF improvement [15].

Bishop et al. explored relationships between reduction in convulsive seizure frequency and everyday executive functions (EF) in a subset of children and young adults with DS treated with adjunctive fenfluramine for 1 year. They carried out a post-hoc analysis of data from children and young adults with DS aged 5-18 years who participated in phase 3 randomized, placebo-controlled clinical trial (core study) followed by completion of at least 1 year of fenfluramine treatment in an OLE study. Eligible children and young adults started the OLE study at $0.2 \mathrm{mg} / \mathrm{kg} /$ day fenfluramine and were titrated to optimal seizure control and tolerability. Parents/caregivers documented convulsive seizure frequency per 28 days (i.e., MCSF) by electronic diary. A parent/caregiver for each child also completed the Behavior Rating Inventory of Executive Function (BRIEF®) parent form, a questionnaire capturing parents'/caregivers' perceptions of everyday EF that was included as a safety measure to assess treatment-related adverse effects on EF during the trial. Ratings on BRIEF ${ }^{\circledR}$ were mapped to the current edition, the BRIEF ${ }^{\circledR} 2$ parent form, and were used to calculate $\mathrm{T}$-scores for the Behavior Regulation Index (BRI), Emotion Regulation Index (ERI), Cognitive Regulation Index (CRI), and Global Executive Composite (GEC). Change in BRIEF®2 Tscores from baseline in the core study to Year 1 of the OLE study was calculated. Spearman's rho correlation coefficients assessed associations between change in BRIEF ${ }^{2} 2$ indexes/composite T-scores and percentage change in MCSF. Children and young adults were divided into 2 groups based on a percentage of MCSF reduction achieved from the prerandomization baseline in the core study to Year 1 of the OLE study: $<50 \%$ and $\geq 50 \%$ MCSF reduction. Changes in the distribution of BRIEF®2 indexes/composite T-scores were compared between MCSF reduction groups using Mann-Whitney U tests. The proportions of children and young adults in these groups who showed clinically meaningful improvement in everyday EF, defined as Reliable Change Index (RCI) values $\geq 95 \%$ certainty relative to a reference population of neurotypically developing healthy volunteers, were then assessed by cross-tabulations and Somers' D tests $(\mathrm{p} \leq 0.05)$. When there was a significant meaningful improvement in an index score, post-hoc analyses using the same statistical methods were conducted to evaluate the individual BRIEF®2 scales composing that index. Supplemental analyses examined the proportions of patients in MCSF reduction groups $<25 \%$ and $\geq 75 \%$ who achieved clinically meaningful improvement or worsening in everyday EF using RCI values $\geq 95 \%$ certainty and $\geq 80 \%$ certainty, respectively, relative to the reference population. 
At the time of analysis, 58 children and young adults (mean age: $11 \pm 4$ years) had reached OLE Year 1 of fenfluramine treatment with a $75 \%$ median percentage reduction in seizure frequency from pre-randomization baseline. Overall, there was a significant correlation between change in MCSF and change in BRIEF®2 T-scores for ERI, but not for BRI, CRI, or GEC. At OLE Year $1,78 \%(\mathrm{n}=45)$ of total children/young adults had $\geq 50 \%$ MCSF reduction $(50 \%[n=29]$ achieved $\geq 75 \%$ MCSF reduction) and $22 \%(n=13)$ of total children/young adults had $<50 \%$ MCSF reduction $(12 \%[\mathrm{n}=7]$ showed $<25 \%$ MCSF reduction). The $\geq 50 \%$ MCSF reduction group was significantly more likely to achieve clinically meaningful improvement (RCI $\geq 95 \%$ certainty) in ERI and CRI than the $<50 \%$ MCSF reduction group. There were no significant differences in the proportions of children and young adults in the $2 \mathrm{MCSF}$ reduction groups showing clinically meaningful worsening (RCI $\geq 80 \%$ certainty) on the BRIEF ${ }^{2} 2$ indexes/composite.

Seventy-eight percent (78\%) of children and young adults treated with adjunctive fenfluramine for 1 year in the OLE study achieved $\geq 50 \%$ reduction in MCSF, for a magnitude of efficacy associated with a significantly greater likelihood of experiencing clinically meaningful improvement in emotion regulation and cognitive regulation [16].

\section{Cardiovascular safety and the effect of food on the pharmacokinetics of fenfluramine}

Patients 2- to 18-years-old with DS who had completed any of three randomized, placebo-controlled clinical trials of fenfluramine were offered enrollment in an OLE study conducted by Lai WW et al. All patients were treated with fenfluramine starting at a dose of $0.2 \mathrm{mg} / \mathrm{kg} / \mathrm{day}$, which was titrated to maximal effect with a dose limit of $0.7 \mathrm{mg} / \mathrm{kg} / \mathrm{day}$ or 0.4 $\mathrm{mg} / \mathrm{kg} /$ day in patients receiving concomitant STP. Standardized echocardiographic examinations were conducted at Week 4 or 6 and then every 3 months during the OLE study to monitor cardiac valve function and structure and pulmonary artery pressure. The primary endpoint for the echocardiography analysis was the number of patients who developed VHD or PAH during treatment.

A total of 232 patients were enrolled in the study. The average age of patients was 9.1 \pm 4.7 years, and $55.2 \%$ were male. The median duration of treatment with fenfluramine was 256 days, and the mean dose of fenfluramine was $0.41 \mathrm{mg} / \mathrm{kg} / \mathrm{day}$. No cases of valvular heart disease or PAH were observed [17]. A different benefit-risk relationship appears to be emerging when fenfluramine is used at low doses for extended periods in young patients with DS [18].

Gammaitoni et al. in their phase I study determined the effect of food on the pharmacokinetic properties of fenfluramine. Healthy nonsmoking subjects aged 18 to 50 years were enrolled in an open-label, crossover, phase I pharmacokinetic and safety profile study and received 2 single $0.8-\mathrm{mg} / \mathrm{kg}$ doses of fenfluramine hydrochloride oral solution (ZX008), 1 after a 10-hour overnight fast and the other 30 minutes after the start of consumption of a high-fat breakfast, in a randomly assigned order. A washout period of at least 9 days separated the 2 treatment periods. Venous blood samples were taken before each dose and periodically for 72 hours after each dose for the determination of concentrations of fenfluramine and its active metabolite norfenfluramine. Plasma pharmacokinetic parameters were estimated for each subject by noncompartmental analysis. 
In the 13 subjects completing both treatment periods, food did not affect the rate or extent of absorption and bioavailability of fenfluramine as assessed by fed vs fasted adjusted geometric mean observed plasma Cmax (59.1 vs $56.7 \mathrm{ng} / \mathrm{mL}$; NS) and AUC0- $\infty$ (1640 vs $1600 \mathrm{ng} \cdot \mathrm{h} / \mathrm{mL}$; NS). Additionally, there was no impact of food on the systemic exposure of norfenfluramine. Seven subjects reported at least 1 treatment-emergent adverse event; all treatment-emergent adverse events were mild in severity [19].

\section{Drug-drug interaction between $\mathrm{ZX008}$ and a regimen of stiripentol, clobazam, and valproate}

Boyd et al. conducted a phase I, open-label, randomized, single-dose, 3-period crossover study assessing pharmacokinetics (PK) and safety of ZX008, a liquid oral formulation of fenfluramine administered with and without a combined AED regimen of STP, valproate (VPA), and clobazam (CLB) (STP regimen). 26 healthy adults were administered the following treatments: ZX008 $0.8 \mathrm{mg} / \mathrm{kg}$; STP 3,500 mg, CLB $20 \mathrm{mg}$, VPA $25 \mathrm{mg} / \mathrm{kg}$ (max. 1,500 mg); and ZX008 $0.8 \mathrm{mg} / \mathrm{kg}+\mathrm{STP}$ regimen. Dose periods were 17 days apart. Blood samples were obtained for 72 hours after drug administration and used to calculate non-compartmental PK parameters.

The statistical bioequivalence-type analysis demonstrated ZX008 had no significant impact on the PK of any drug in the STP regimen, while the STP regimen moderately affected fenfluramine PK. The 3-drug combination increased the geometric mean Cmax, AUC0-t, and AUC0-inf of fenfluramine while reducing the Cmax and AUC0-t of its major metabolite, norfenfluramine (norFFA). AEs were mild to moderate and resolved spontaneously. ZX008 + STP regimen co-administration to healthy adult subjects modestly impacted the number but not the severity of AEs [20].

\section{CONCLUSIONS}

1. In DS, fenfluramine provided a significantly greater reduction in convulsive seizure frequency compared with placebo and was generally well-tolerated. In children and young adults with DS, the magnitude of reduction in MCSF after long-term treatment with adjunctive fenfluramine was associated with clinically meaningful levels of improvement in everyday EF.

2. There is a low risk of developing VHD and PAH when used to treat patients with DS with fenfluramine. The observed cardiovascular safety in a group of patients with DS who have been receiving low-dose fenfluramine for a long period suggests that, unlike in the adult obese population, the benefits of the drug in DS treatment may outweigh the risks. The side effects that occurred with it were mild, including decreased appetite, diarrhea, pyrexia, nasopharyngitis, fatigue, somnolence, fever, and weight loss. The bioequivalence and tolerability of single oral doses of ZX008 in the fed and fasted states support ZX008 administration without regard to meals.

3. STP regimen had a moderate impact on the ZX008 and norFFA pharmacokinetics and ZX008 had no significant impact on the 3 STP regimen drugs. ZX008 would not be 
expected to alter the clinical response of patients to this regimen through an effect on pharmacokinetics. A downward dose adjustment of ZX008 may be warranted when administering these drugs together.

4. Fenfluramine may represent a new important treatment option for DS.

\author{
Abbreviations: \\ DS - Dravet syndrome \\ AED - antiepileptic drug \\ STP - stiripentol \\ MCSF - monthly convulsive seizure frequency \\ PAH - pulmonary arterial hypertension \\ VHD - valvular heart disease \\ OLE - open-label extension \\ AEs - adverse events \\ NNTs - numbers needed to treat \\ EF - executive functions \\ BRIEF® - Behavior Rating Inventory of Executive Function \\ BRI - Behavior Regulation Index \\ ERI - Emotion Regulation Index \\ CRI - Cognitive Regulation Index \\ GEC - Global Executive Composite \\ RCI - Reliable Change Index \\ ZX008 - fenfluramine hydrochloride oral solution \\ PK - pharmacokinetics \\ VPA - valproate \\ CLB - clobazam \\ norFFA - norfenfluramine
}

\title{
Author contributions
}

All the authors made substantial contributions to the conception or design of the work, or the acquisition, analysis, or interpretation of data for the work; and were involved in drafting the work and revising it critically for important intellectual content; and gave final approval for the version to be published; and agree to be accountable for all aspects of the work in ensuring that questions related to the accuracy or integrity of any part of the work are appropriately investigated and resolved.

\section{Financial \& competing interests disclosure}

This study was not sponsored and funded.

\section{Ethical conduct of research}

No ethical approval was required for this research 


\section{Data sharing statement}

Any additional datasets that are not provided as part of the manuscript or as supplementary materials are available from the corresponding author on reasonable request.

\section{LIST OF REFERENCES:}

1. Zhang L, Li W, Wang C. Efficacy and safety of fenfluramine in patients with Dravet syndrome: A meta-analysis. Acta Neurol Scand. 2021 Apr;143(4):339-348. doi: 10.1111/ane.13387. Epub 2020 Dec 17. PMID: 33336426.

2. Simon K, Sheckley H, Anderson CL, Liu Z, Carney PR. A review of fenfluramine for the treatment of Dravet syndrome patients. Curr Res Pharmacol Drug Discov. 2021 Dec 16;3:100078. doi: 10.1016/j.crphar.2021.100078. PMID: 34988433; PMCID: PMC8695265.

3. Polster T. Individualized treatment approaches: Fenfluramine, a novel antiepileptic medication for the treatment of seizures in Dravet syndrome. Epilepsy Behav. 2019 Feb;91:99-102. doi: 10.1016/j.yebeh.2018.08.021. Epub 2018 Sep 28. PMID: 30269941 .

4. Wheless JW, Fulton SP, Mudigoudar BD. Dravet Syndrome: A Review of Current Management. Pediatr Neurol. 2020 Jun;107:28-40. doi: 10.1016/j.pediatrneurol.2020.01.005. Epub 2020 Jan 31. PMID: 32165031.

5. Gogou M, Cross JH. Fenfluramine as antiseizure medication for epilepsy. Dev Med Child Neurol. 2021 Aug;63(8):899-907. doi: 10.1111/dmcn.14822. Epub 2021 Feb 9. PMID: 33565102.

6. Sullivan J, Simmons R. Fenfluramine for treatment-resistant epilepsy in Dravet syndrome and other genetically mediated epilepsies. Drugs Today (Barc). 2021 Jul;57(7):449-454. doi: 10.1358/dot.2021.57.7.3284619. PMID: 34268532.

7. Schoonjans AS, Lagae L, Ceulemans B. Low-dose fenfluramine in the treatment of neurologic disorders: experience in Dravet syndrome. Ther Adv Neurol Disord. 2015 Nov;8(6):328-38. doi: 10.1177/1756285615607726. PMID: 26600876; PMCID: PMC4643872.

8. Odi R, Invernizzi RW, Gallily T, Bialer M, Perucca E. Fenfluramine repurposing from weight loss to epilepsy: What we do and do not know. Pharmacol Ther. 2021 Oct;226:107866. doi: 10.1016/j.pharmthera.2021.107866. Epub 2021 Apr 22. PMID: 33895186.

9. Balagura G, Cacciatore M, Grasso EA, Striano P, Verrotti A. Fenfluramine for the Treatment of Dravet Syndrome and Lennox-Gastaut Syndrome. CNS Drugs. 2020 Oct;34(10):1001-1007. doi: 10.1007/s40263-020-00755-z. PMID: 32875491.

10. Martin P, de Witte PAM, Maurice T, Gammaitoni A, Farfel G, Galer B. Fenfluramine acts as a positive modulator of sigma-1 receptors. Epilepsy Behav. 2020 Apr;105:106989. doi: 10.1016/j.yebeh.2020.106989. Epub 2020 Mar 10. PMID: 32169824.

11. Lagae L, Sullivan J, Knupp K, Laux L, Polster T, Nikanorova M, Devinsky O, Cross JH, Guerrini R, Talwar D, Miller I, Farfel G, Galer BS, Gammaitoni A, Mistry A, Morrison G, Lock M, Agarwal A, Lai WW, Ceulemans B; FAiRE DS Study Group. 
Fenfluramine hydrochloride for the treatment of seizures in Dravet syndrome: a randomised, double-blind, placebo-controlled trial. Lancet. 2019 Dec 21;394(10216):2243-2254. doi: 10.1016/S0140-6736(19)32500-0. Epub 2019 Dec 17. PMID: 31862249.

12. Nabbout R, Mistry A, Zuberi S, Villeneuve N, Gil-Nagel A, Sanchez-Carpintero R, Stephani U, Laux L, Wirrell E, Knupp K, Chiron C, Farfel G, Galer BS, Morrison G, Lock M, Agarwal A, Auvin S; FAiRE, DS Study Group. Fenfluramine for TreatmentResistant Seizures in Patients With Dravet Syndrome Receiving Stiripentol-Inclusive Regimens: A Randomized Clinical Trial. JAMA Neurol. 2020 Mar 1;77(3):300-308. doi: 10.1001/jamaneurol.2019.4113. PMID: 31790543; PMCID: PMC6902175.

13. Sullivan J, Scheffer IE, Lagae L, Nabbout R, Pringsheim M, Talwar D, Polster T, Galer B, Lock M, Agarwal A, Gammaitoni A, Morrison G, Farfel G. Fenfluramine $\mathrm{HCl}$ (Fintepla ${ }^{\circledR}$ ) provides long-term clinically meaningful reduction in seizure frequency: Analysis of an ongoing open-label extension study. Epilepsia. 2020 Nov;61(11):2396-2404. doi: 10.1111/epi.16722. Epub 2020 Oct 19. PMID: 33078386; PMCID: PMC7756901.

14. Specchio N, Pietrafusa N, Doccini V, Trivisano M, Darra F, Ragona F, Cossu A, Spolverato S, Battaglia D, Quintiliani M, Luigia Gambardella M, Rosati A, Mei D, Granata T, Dalla Bernardina B, Vigevano F, Guerrini R. Efficacy and safety of Fenfluramine hydrochloride for the treatment of seizures in Dravet syndrome: A realworld study. Epilepsia. 2020 Nov;61(11):2405-2414. doi: 10.1111/epi.16690. Epub 2020 Sep 18. PMID: 32945537.

15. Sullivan J, Perry MS, Wheless JW, Galer B, Gammaitoni A. Fenfluramine responder analyses and numbers needed to treat: Translating epilepsy trial data into clinical practice. Eur J Paediatr Neurol. 2021 Mar;31:10-14. doi: 10.1016/j.ejpn.2021.01.005. Epub 2021 Jan 22. PMID: 33540241.

16. Bishop KI, Isquith PK, Gioia GA, Gammaitoni AR, Farfel G, Galer BS, Nabbout R, Wirrell EC, Polster T, Sullivan J. Improved everyday executive functioning following profound reduction in seizure frequency with fenfluramine: Analysis from a phase 3 long-term extension study in children/young adults with Dravet syndrome. Epilepsy Behav. 2021 Aug;121(Pt A):108024. doi: 10.1016/j.yebeh.2021.108024. Epub 2021 May 20. PMID: 34023810.

17. Lai WW, Galer BS, Wong PC, Farfel G, Pringsheim M, Keane MG, Agarwal A. Cardiovascular safety of fenfluramine in the treatment of Dravet syndrome: Analysis of an ongoing long-term open-label safety extension study. Epilepsia. 2020 Nov;61(11):2386-2395. doi: 10.1111/epi.16638. Epub 2020 Aug 18. PMID: 32809271 ; PMCID: PMC7754414.

18. Schoonjans AS, Marchau F, Paelinck BP, Lagae L, Gammaitoni A, Pringsheim M, Keane MG, Ceulemans B. Cardiovascular safety of low-dose fenfluramine in Dravet syndrome: a review of its benefit-risk profile in a new patient population. Curr Med Res Opin. 2017 Oct;33(10):1773-1781. doi: 10.1080/03007995.2017.1355781. Epub 2017 Jul 31. PMID: 28704161.

19. Gammaitoni A, Smith S, Boyd B. The Lack of Effect of Food on the Pharmacokinetics of ZX008 (Fenfluramine Oral Solution): Results of a Single-dose, 
Two-period Crossover Study. Clin Ther. 2018 Aug;40(8):1338-1346. doi: 10.1016/j.clinthera.2018.05.013. Epub 2018 Jun 23. PMID: 29941151.

20. Boyd B, Smith S, Gammaitoni A, Galer BS, Farfel GM. A phase I, randomized, openlabel, single-dose, 3-period crossover study to evaluate the drug-drug interaction between ZX008 (fenfluramine $\mathrm{HCl}$ oral solution) and a regimen of stiripentol, clobazam, and valproate in healthy subjectsisep. Int J Clin Pharmacol Ther. 2019 Jan;57(1):11-19. doi: 10.5414/CP203276. PMID: 30336805; PMCID: PMC6298132. 